\title{
VARIABILITY OF PHYSICAL AND CONSOLIDATION TEST RESULTS FOR RELATIVELY UNIFORM CLAY SAMPLES RETRIEVED FROM OSAKA BAY
}

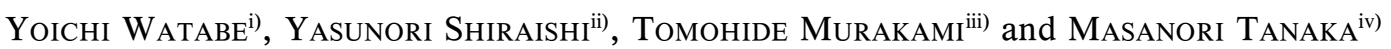

\begin{abstract}
Samples collected from both Holocene and Pleistocene layers in Osaka Bay were examined in this study. The objective of this study is to evaluate variations of soil parameters in a sample length of about one meter. The retrieved samples from EL. (elevation) -37.5 to $-38.5 \mathrm{~m}$ and from EL. -125.5 to $-126.5 \mathrm{~m}$ with a length of about one meter were divided into every $25 \mathrm{~mm}$ long to trim consolidation specimens. Variations of soil parameters obtained from laboratory tests were evaluated. Clay microfabric was also evaluated by scanning electron microscopy (SEM) and mercury intrusion porosimetry (MIP). The clay layers are relatively homogeneous with variation coefficient CV in a range of 0.025 to 0.12 for the consolidation parameters $\left(e, p_{\mathrm{c}}^{\prime}, C_{\mathrm{c}}\right.$ and $\left.c_{\mathrm{v}}\right)$. CV of void ratio $e$ is only 0.025 to 0.056 . In contrast, $\mathrm{CV}$ values of the other consolidation parameters are significantly greater than this, but the average is less than 0.1 . It can be concluded that $\mathrm{CV}$ of soil consolidation parameters for the homogeneous natural clay deposits dealt in this study is less than about 0.1 . These variations are mainly influenced by sedimentary environment. Even the soil is said to be homogeneous, because the specimen size for the laboratory tests is sufficiently large in consideration of microscopic heterogeneity obtained from SEM and MIP.
\end{abstract}

Key words: clay, consolidation, soil parameters, variation (IGC: C6/D6)

\section{INTRODUCTION}

Osaka Bay clay retrieved from the seabed was investigated for the Kansai International Airport project. The airport located $35 \mathrm{~km}$ southwest from the center of Osaka City was constructed on an artificial island that was reclaimed $5 \mathrm{~km}$ off the Senshu area in Osaka Bay. The first phase of the Airport with only one runway is in operation since September, 1994, and the second phase is under construction aimed the second runway (will open in 2007) paralleling to the first one. Generally in practice, laboratory tests are conducted for specimens trimmed in an interval of more than one meter depth. Soil parameters obtained from consolidation tests conducted at every two meters depth in Osaka Bay showed a significant variation (Tanaka et al., 2003a). It has not been clarified yet whether the variation was derived from geological heterogeneity; even Tanaka et al. (2003b) discussed test results of a precise cone penetration test applied to greater depths.

In this study, samples collected from both Holocene and Pleistocene layers were examined on their physical and consolidation properties. The objective of this study is to evaluate variations of soil parameters in a length of about one meter. Variation of clay microfabric observed with scanning electron microscope (SEM) was also statistically analyzed in association with pore entrance distribution obtained by mercury intrusion porosimetry (MIP).

Most of Japanese marine clays are very homogeneous; however, they are not perfectly homogeneous because they deposited in a natural condition. One of the objectives of this study is to evaluate the reliability of a limited number of test results in practice for the marine clay.

Undisturbed samples used in this paper were obtained from the Osaka Bay during the in situ investigation for the second construction phase of the Kansai International Airport. A piston sampler of hydraulic operated type was used for soft and slightly hard clays up to EL. (elevation) $-120 \mathrm{~m}$, and a Denison sampler was used for hard clays deeper than EL. $-120 \mathrm{~m}$. Both sampling methods were carried out by the Port and Airport Research Institute (PARI), formerly known as the Port and Harbour Research Institute (PHRI) wire line system (Horie et al., 1984; Kanda et al., 1991), which was also illustrated in Watabe et al., (2002). The inner diameter and the length

i) Port and Airport Research Institute, Japan (watabe@ipc.pari.go.jp).

ii) Nippon Koei Co., Ltd., Japan.

iii) Saeki Kensetsu Kogyo Co., Ltd., Japan.

iv) Port and Airport Research Institute, Japan.

The manuscript for this paper was received for review on June 1, 2006; approved on March 26, 2007.

Written discussions on this paper should be submitted before March 1, 2008 to the Japanese Geotechnical Society, 4-38-2, Sengoku, Bunkyo$\mathrm{ku}$, Tokyo 112-0011, Japan. Upon request the closing date may be extended one month. 
of sampling tube are 80 and $1000 \mathrm{~mm}$, respectively. At the boring point, the water depth was $19 \mathrm{~m}$, the thickness of Holocene clay layer was $25 \mathrm{~m}$, and the Pleistocene clay layer deposited was more than $350 \mathrm{~m}$ thick alternately with some sandy layers. The sampling method and the characteristics of the soils collected from the Osaka Bay were reported in detail by Horie et al. (1984), Ishii et al. (1984), Tsuchida et al. (1984), Kanda et al. (1991), Akai et al. (1995), Akai (2000) and Watabe et al. (2002). According to Watabe and Tsuchida (2001a), the residual effective stress is about one fifth of the effective overburden stress $\sigma_{\mathrm{v} 0}^{\prime}$ and the sample quality is classified as very good. The consolidation settlement was discussed by Nakase (1987) and Duncan (1993), and undrained shear strength was discussed by Watabe et al. (2002).

The Holocene clay deposited within the last 10,000 years. The underlying Pleistocene deposit includes several major sandy soil layers between the clay layers. The clay at EL. $-140 \mathrm{~m}$ was deposited 270,000 years ago and that at EL. $-210 \mathrm{~m}$ was deposited 440,000 years ago. Figure 1 shows the soil profile and values of liquid limit $\left(w_{\mathrm{L}}\right)$, plastic limit $\left(w_{\mathrm{p}}\right)$ and natural water content $\left(w_{\mathrm{n}}\right)$; contents of clay $(\leq 5 \mu \mathrm{m})$, silt $(>5 \mu \mathrm{m}$ and $\leq 75 \mu \mathrm{m})$, sand ( $>75 \mu \mathrm{m}$ and $\leq 2 \mathrm{~mm}$ ); density of soil particles $\left(\rho_{\mathrm{s}}\right)$; void ratio $(e)$; consolidation yield stress ( $p_{\mathrm{c}}^{\prime}$ ) obtained by CRS (constant rate of strain) consolidation tests with an axial strain rate of $0.01 \% / \mathrm{min}$; and overconsolidation ratio (OCR) defined as $p_{\mathrm{c}}^{\prime} / \sigma_{\mathrm{v} 0}^{\prime}$, where $\sigma_{\mathrm{v} 0}^{\prime}$ is calculated by summing the effective unit weight of clay as $\gamma^{\prime}=6.9 \mathrm{kN} / \mathrm{m}^{3}$. The OCR is essentially constant with depth and equals 1.50 (standard deviation $\mathrm{SD}=0.16$ ), indicating slight overconsolidation, but it is, generally, in normal consolidation from mechanical stress history (Akai et al., 1995; Akai, 2000; Watabe et al., 2002). Tanaka and Locat (1999) indicated that the consolidation behavior is possibly characterized by diatom fossils which are abundantly contained in the Osaka Bay clay. The greater the abundance of diatom fossils, the greater the contraction characterized.

\section{TEST AND OBSERVATION PROGRAM}

In this study, samples retrieved from both a Holocene layer at EL. $-38 \mathrm{~m}$ (G.L. - $19 \mathrm{~m})$ and a Pleistocene layer at EL. $-126 \mathrm{~m}$ (G.L. $-107 \mathrm{~m}$ ) were examined. Two retrieved samples with a length of about one meter and a diameter of $80 \mathrm{~mm}$ were divided into every $25 \mathrm{~mm}$ of length to trim consolidation specimens with $60 \mathrm{~mm}$ in diameter and $20 \mathrm{~mm}$ in height. The following parameters obtained from laboratory tests were evaluated: i) natural water content $\left(w_{\mathrm{n}}\right)$; ii) Atterberg's limits (liquid limit $\left(w_{\mathrm{L}}\right)$ and plastic limit $\left.\left(w_{\mathrm{p}}\right)\right)$; iii) contents of clay, silt and sand; iv) soil particle density $\left(\rho_{\mathrm{s}}\right)$; v) soil bulk density $\left(\rho_{\mathrm{t}}\right)$; vi) void ratio (e); vii) consolidation yield stress $\left(p_{\mathrm{c}}^{\prime}\right)$; viii) compression index $\left(C_{\mathrm{c}}\right)$; and ix) coefficient of consolidation $\left(c_{\mathrm{v}}\right)$. Clay microfabric was also evaluated by $\mathrm{x}$ ) scanning electron microscopy (SEM) and xi) mercury intrusion porosimetry (MIP). The test program corresponding to the each specimen divided from the samples is listed in Table 1.

$w_{\mathrm{n}}, w_{\mathrm{L}}, w_{\mathrm{p}}, \rho_{\mathrm{s}}$ and grain size distribution were first examined before carrying out the series of consolidation tests by using soil chips from specimen trimming. Constant rate of strain consolidation tests (CRS tests) were then carried out for the trimmed clay specimens. $\rho_{\mathrm{t}}, e, p_{\mathrm{c}}^{\prime}$, compression index defined as the gradient of the steepest slope in $e-\log p$ relationship $\left(C_{\mathrm{c}}\right)$, compression index at a consolidation pressure greater than $5000 \mathrm{kPa}$ in $e-\log p$ relationship $\left(C_{\mathrm{c}}^{*}\right)$ and $c_{\mathrm{v}}$ defined as a constant value in normal consolidation were obtained from the CRS tests. The CRS tests were conducted with a back pressure of $98.1 \mathrm{kPa}$ and in a strain rate of $0.02 \% / \mathrm{min}$.

In addition, the soil chips from specimen trimming were also examined by SEM and MIP. As a fundamental condition of the soil specimen for SEM observation, it is necessary to remove the pore water of clayey soil completely, because the observation chamber of SEM is in vacuum state. Freeze-cut-drying method is believed to be an effective method (Shi et al., 1999; Kang et al., 2003;
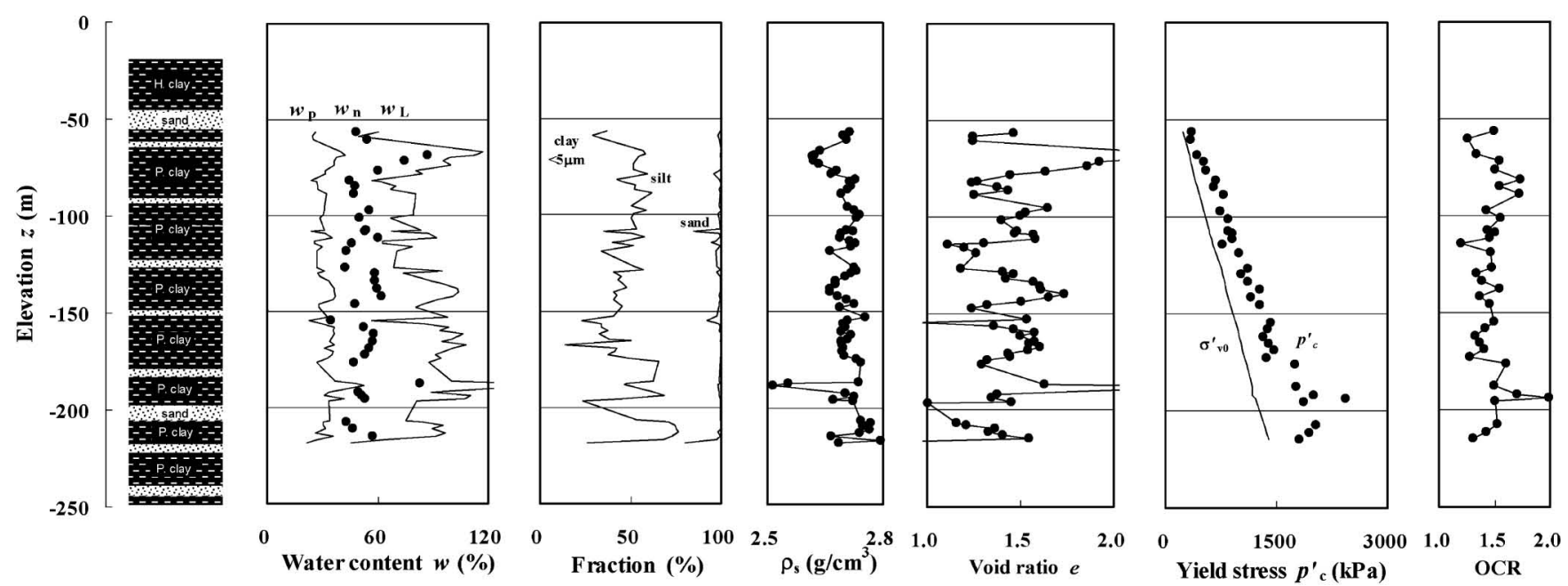

Fig. 1. Physical and consolidation profiles of Osaka Bay clay 
Table 1. List of tested samples

\begin{tabular}{|c|c|c|c|c|c|c|c|c|c|c|c|}
\hline $\begin{array}{c}\text { Elevation } \\
\text { E.L. }(-m)\end{array}$ & $\begin{array}{l}\text { Atterberg } \\
\text { limits }\end{array}$ & $\begin{array}{l}\text { Grain } \\
\text { size }\end{array}$ & CRS & SEM & MIP & $\begin{array}{l}\text { Elevation } \\
\text { E.L. }(-\mathrm{m})\end{array}$ & $\begin{array}{l}\text { Atterberg } \\
\text { limits }\end{array}$ & $\begin{array}{l}\text { Grain } \\
\text { size }\end{array}$ & CRS & SEM & MIP \\
\hline $37.500-37.525$ & \multirow{4}{*}{0} & 0 & 0 & & 0 & $125.500-125.525$ & \multirow{4}{*}{0} & \multirow{4}{*}{$\bigcirc$} & & & 0 \\
\hline $37.525-37.550$ & & 0 & 0 & 0 & 0 & $125.525-125.550$ & & & & 0 & 0 \\
\hline $37.550-37.575$ & & 0 & 0 & & 0 & $125.550-125.575$ & & & & & 0 \\
\hline $37.575-37.600$ & & 0 & 0 & & 0 & $125.575-125.600$ & & & 0 & & 0 \\
\hline $37.600-37.625$ & \multirow{4}{*}{$\bigcirc$} & & 0 & & O & $125.600-125.625$ & \multirow{4}{*}{$\bigcirc$} & \multirow{4}{*}{$\bigcirc$} & 0 & & 0 \\
\hline $37.625-37.650$ & & $\bigcirc$ & 0 & $\bigcirc$ & 0 & $125.625-125.650$ & & & & 0 & 0 \\
\hline $37.650-37.675$ & & 0 & 0 & & 0 & $125.650-125.675$ & & & $\bigcirc$ & & 0 \\
\hline $37.675-37.700$ & & 0 & 0 & & $\bigcirc$ & $125.675-125.700$ & & & 0 & & 0 \\
\hline $37.700-37.725$ & \multirow{4}{*}{0} & 0 & 0 & & 0 & $125.700-125.725$ & \multirow{4}{*}{0} & \multirow{4}{*}{0} & & & \\
\hline $37.725-37.750$ & & 0 & 0 & & 0 & $125.725-125.750$ & & & 0 & & 0 \\
\hline $37.750-37.775$ & & 0 & 0 & & 0 & $125.750-125.775$ & & & & 0 & 0 \\
\hline $37.775-37.800$ & & 0 & 0 & 0 & $\bigcirc$ & $125.775-125.800$ & & & 0 & & 0 \\
\hline $37.800-37.825$ & \multirow{4}{*}{$\bigcirc$} & 0 & 0 & & & $125.800-125.825$ & \multirow{4}{*}{$\bigcirc$} & \multirow{4}{*}{$\bigcirc$} & 0 & 0 & 0 \\
\hline $37.825-37.850$ & & 0 & 0 & & 0 & $125.825-125.850$ & & & 0 & & 0 \\
\hline $37.850-37.875$ & & 0 & 0 & 0 & 0 & $125.850-125.875$ & & & 0 & & 0 \\
\hline $37.875-37.900$ & & 0 & 0 & & 0 & $125.875-125.900$ & & & 0 & & 0 \\
\hline $37.900-37.925$ & \multirow{4}{*}{$\bigcirc$} & $\bigcirc$ & $\bigcirc$ & & 0 & $125.900-125.925$ & \multirow{4}{*}{0} & 0 & $\bigcirc$ & & $\bigcirc$ \\
\hline $37.925-37.950$ & & 0 & 0 & & 0 & $125.925-125.950$ & & 0 & 0 & $\bigcirc$ & 0 \\
\hline $37.950-37.975$ & & 0 & 0 & 0 & 0 & $125.950-125.975$ & & 0 & 0 & & 0 \\
\hline $37.975-38.000$ & & 0 & 0 & & 0 & $125.975-126.000$ & & 0 & 0 & & 0 \\
\hline $38.000-38.025$ & \multirow{4}{*}{$\bigcirc$} & 0 & 0 & 0 & 0 & $126.000-126.025$ & \multirow{4}{*}{0} & 0 & 0 & 0 & 0 \\
\hline $38.025-38.050$ & & 0 & 0 & & $\bigcirc$ & $126.025-126.050$ & & & & & \\
\hline $38.050-38.075$ & & 0 & 0 & & $\bigcirc$ & $126.050-126.075$ & & $\bigcirc$ & $\bigcirc$ & & $\bigcirc$ \\
\hline $38.075-38.100$ & & 0 & 0 & & $\bigcirc$ & $126.075-126.100$ & & 0 & 0 & & 0 \\
\hline $38.100-38.125$ & \multirow{4}{*}{$\bigcirc$} & 0 & 0 & 0 & 0 & $126.100-126.125$ & \multirow{4}{*}{$\bigcirc$} & 0 & 0 & & 0 \\
\hline $38.125-38.150$ & & 0 & 0 & & 0 & $126.125-126.150$ & & 0 & 0 & & $\bigcirc$ \\
\hline $38.150-38.175$ & & 0 & 0 & & 0 & $126.150-126.175$ & & 0 & 0 & 0 & $\bigcirc$ \\
\hline $38.175-38.200$ & & 0 & 0 & 0 & 0 & $126.175-126.200$ & & 0 & 0 & & 0 \\
\hline $38.200-38.225$ & \multirow{4}{*}{$\bigcirc$} & $\bigcirc$ & 0 & $\bigcirc$ & $\bigcirc$ & $126.200-126.225$ & \multirow{4}{*}{$\bigcirc$} & 0 & $\bigcirc$ & & 0 \\
\hline $38.225-38.250$ & & 0 & 0 & 0 & 0 & $126.225-126.250$ & & 0 & 0 & & 0 \\
\hline $38.250-38.275$ & & 0 & 0 & & 0 & $126.250-126.275$ & & 0 & 0 & 0 & 0 \\
\hline $38.275-38.300$ & & 0 & 0 & & 0 & $126.275-126.300$ & & 0 & 0 & & 0 \\
\hline $38.300-38.325$ & & & & & & $126.300-126.325$ & \multirow{4}{*}{0} & & & & \\
\hline $38.325-38.350$ & & & & & & $126.325-126.350$ & & & & & \\
\hline $38.350-38.375$ & & & & & & $126.350-126.375$ & & & & & \\
\hline $38.375-38.400$ & & & & & & $126.375-126.400$ & & & & & \\
\hline $38.400-38.425$ & & & & & & $126.400-126.425$ & \multirow{4}{*}{0} & & & & \\
\hline $38.425-38.450$ & & & & & & $126.425-126.450$ & & & & & \\
\hline $38.450-38.475$ & & & & & & $126.450-126.475$ & & & & & \\
\hline $38.475-38.500$ & & & & & & $126.475-126.500$ & & & & & \\
\hline
\end{tabular}


Watabe et al., 2004). This method was adopted in this study both to minimize the sample disturbance caused by either shrinkage or expansion of porous wet media and to obtain a flat observation surface. In freeze drying, a soil sample trimmed to an appropriate size and shape is immersed into liquid nitrogen $\left(-196^{\circ} \mathrm{C}\right)$ for instant freezing to avoid formation of crystallized ice in pores. The crystallized ice consequently leads to volumetric expansion of the soil. Then, the frozen specimen is transferred to the vacuumed chamber of a freeze dryer for sublimation at least for 24 hours. The sample size is about $3 \mathrm{~mm}$ in thickness and 30 to $40 \mathrm{~mm}$ in length of stick shape. For SEM observation, to determine the observation surface of specimen, fracturing was conducted at freeze condition. This corresponds to the freeze-cut-drying method in which a frozen sample is cut by tensional fracturing (Shi et al., 1999). Tensional fracturing is done by holding one end of the sample and impacting a strike with a swinging hammer causing a tensional cut in the middle part of the sample. This is to avoid any disturbance accompanied by either knife cutting or shearing. It is noted that tensional cut is necessary only for SEM, but not for MIP.

In the SEM observation, four edges of a square with a side of $0.3 \mathrm{~mm}$ in each specimen were photographed by four different magnifications at 5000, 2500, 1000 and 500 times. The SEM photographs were image-analyzed by transforming the photographed image in gray scale from 0 to 255 into a binarized black and white image with a certain threshold value. In this study, the threshold value was set in 200. The black percentage in the binarized black and white image was calculated.
The specimen height for the consolidation test is 20 $\mathrm{mm}$, while the width of SEM image in a magnification of 500 times is about $0.3 \mathrm{~mm}$. The scale continuity in this discussion is retained, because the scale gap between two approaches from laboratory tests and microscopy are only 70 times. MIP can quantitatively evaluate the pore size distribution which is an important component of the fabric observed in SEM images.

\section{TEST RESULTS AND DISCUSSIONS}

\section{Variation of Physical Properties}

Physical properties $\left(w_{\mathrm{n}}, w_{\mathrm{p}}, w_{\mathrm{L}}\right.$, particle size fractions, $\rho_{\mathrm{s}}$ and $e$ ) of the Holocene and the Pleistocene clays are shown in Figs. 2 and 3, respectively. Frequencies, mean value (MV) and standard deviation (SD) of these parameters are also shown in the figures. Both clays have essentially common properties as $w_{\mathrm{L}}=80 \%, w_{\mathrm{p}}=30 \%$, plasticity index $\left(I_{\mathrm{p}}\right)$ of 50 , clay fraction of 30 to $40 \%$, sand fraction of less than $20 \%$. The $w_{\mathrm{n}}$ of the Holocene clay $(73.09 \pm 2.06 \%)$ is slightly less than $w_{\mathrm{L}}$ (i.e. liquidity index $I_{\mathrm{L}}$ of about 0.86 is slightly smaller than unity), and $w_{\mathrm{n}}$ of the Pleistocene clay $(41.76 \pm 2.19 \%)$ is slightly larger than $w_{\mathrm{p}}$ (i.e. liquidity index $I_{\mathrm{L}}$ of 0.24 is slightly larger than zero). SD of $w_{\mathrm{n}}$ for the both clays is only about $2 \%$. Corresponding to this, the profile of $\rho_{\mathrm{t}}$ of the Holocene clay $\left(1.550 \pm 0.010 \mathrm{Mg} / \mathrm{m}^{3}\right)$ is very homogeneous. In contrast, that of the Pleistocene clay $\left(\rho_{\mathrm{t}}=1.726 \pm 0.030\right.$ $\mathrm{Mg} / \mathrm{m}^{3}$ ) shows significant variation caused by a higher $\rho_{\mathrm{t}}$ value close to $1.8 \mathrm{Mg} / \mathrm{m}^{3}$ at around EL. $-126.05 \mathrm{~m}$. In fact, $w_{\mathrm{n}}$ also shows a slight smaller value at this depth.

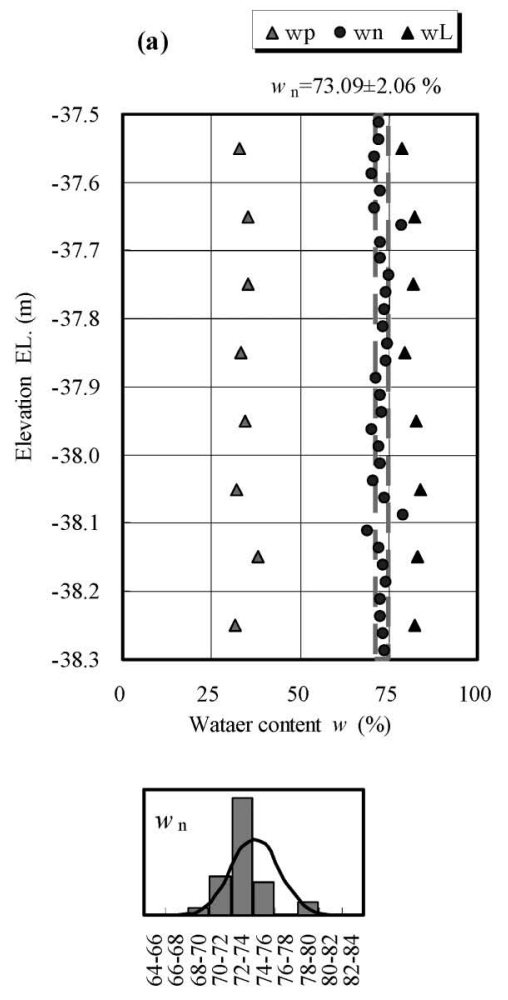

(b)
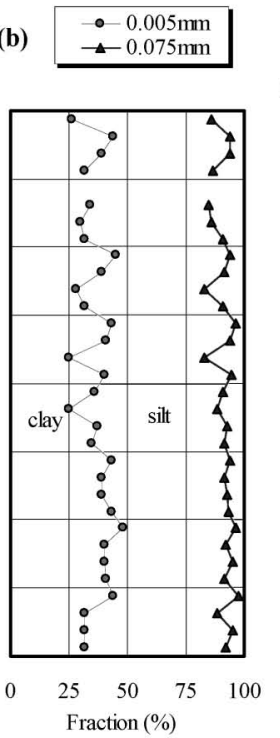

(c)
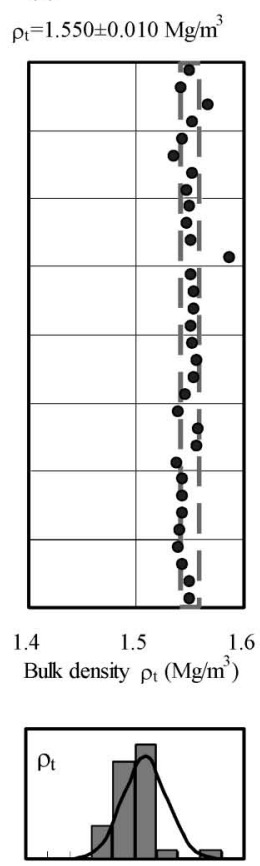

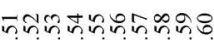
ò่ (d)

$\rho_{\mathrm{s}}=2.644 \pm 0.028 \mathrm{Mg} / \mathrm{m}^{3}$

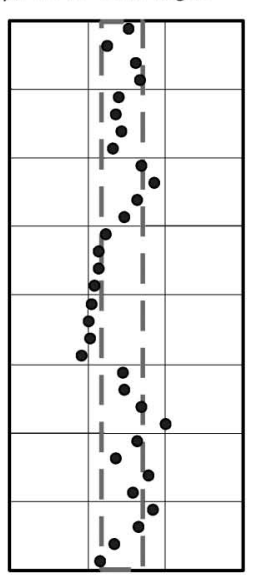

$\begin{array}{llll}2.5 & 2.6 & 2.7 & 2.8\end{array}$

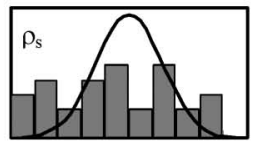

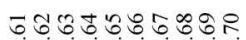

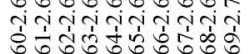

(e) $e=1.954 \pm 0.058$
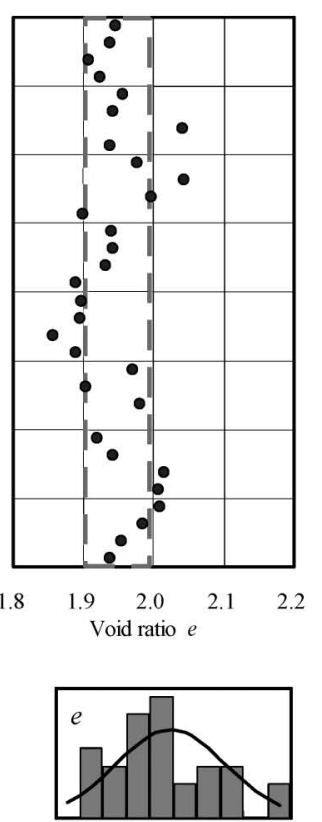

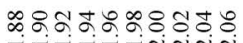
ठ์ -

Fig. 2. Profiles of physical properties with depth in the Holocene clay 
(a)
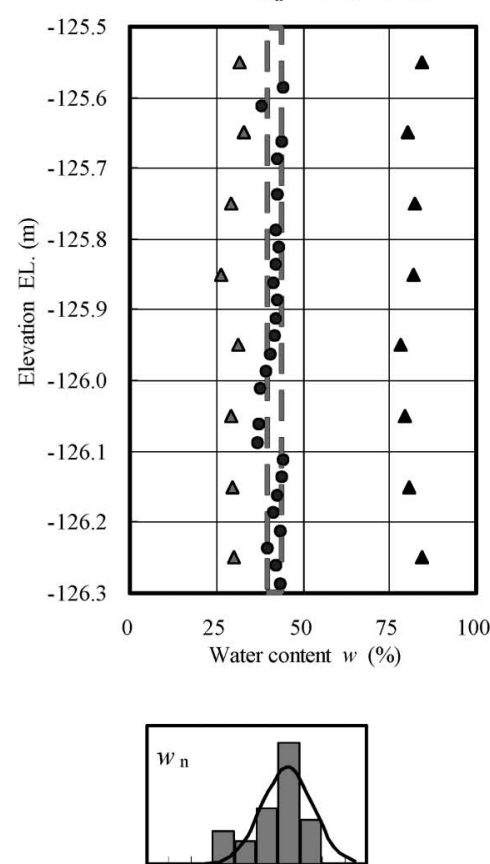

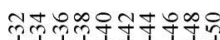

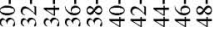
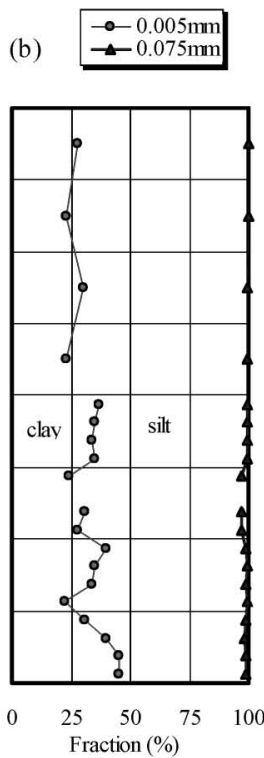

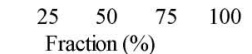

(c)

$\rho_{\mathrm{t}}=1.726 \pm 0.030 \mathrm{Mg} / \mathrm{m}^{3}$

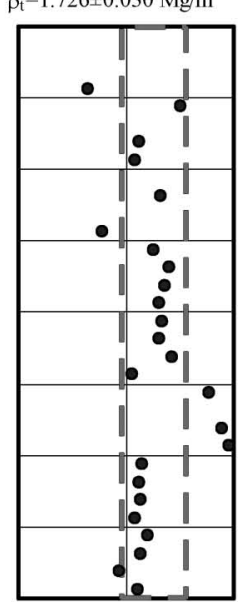

1.7

Bulk density $\rho_{\mathrm{t}}\left(\mathrm{Mg} / \mathrm{m}^{3}\right)$

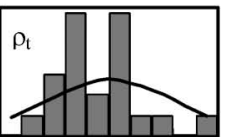

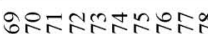
क्षoำ (d)

$\rho_{\mathrm{s}}=2.695 \pm 0.013 \mathrm{Mg} / \mathrm{m}^{3}$
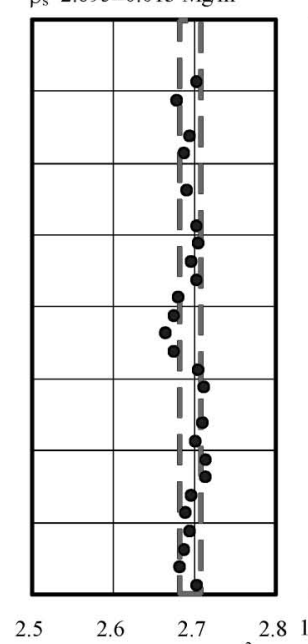

Particle density $\rho_{\mathrm{S}}\left(\mathrm{Mg} / \mathrm{m}^{3}\right)$

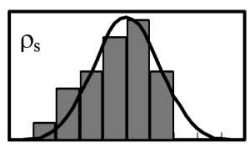

능유Nㅠ n.

riging ing (e)

$e=1.215 \pm 0.068$
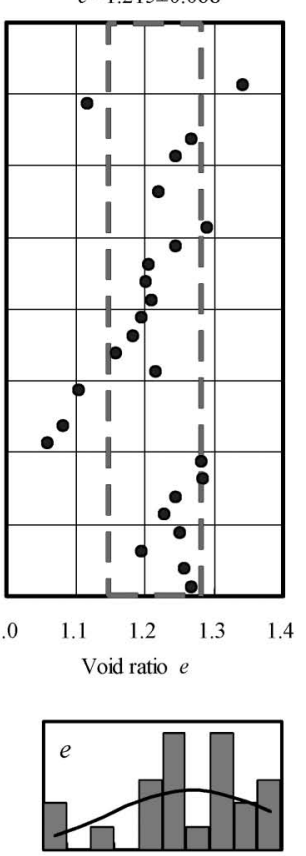

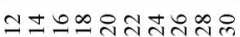

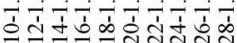

Fig. 3. Profiles of physical properties with depth in the Pleistocene clay

Comparing between SD/MV (=CV: variation coefficient) values for $w_{\mathrm{n}}$ and $\rho_{\mathrm{t}}(0.028$ and 0.006 respectively for the Holocene clay and 0.052 and 0.017 respectively for the Pleistocene clay), it can be said that $w_{\mathrm{n}}$ is more sensitive than $\rho_{\mathrm{t}}$.

The profile of $\rho_{\mathrm{s}}$ of the Holocene clay $(=2.644 \pm 0.028$ $\mathrm{Mg} / \mathrm{m}^{3}$ ) is slight variable with $\mathrm{CV}$ of 0.011 , corresponding to the profile of $e(1.954 \pm 0.058$ with $\mathrm{CV}$ of $0.030)$. The $\rho_{\mathrm{s}}$ shows high values of 2.69 to $2.70 \mathrm{Mg} / \mathrm{m}^{3}$ at around EL. $-37.75 \mathrm{~m}$ and $-38.15 \mathrm{~m}$ resulting higher $e$ values at these depths. This fact means that, if MV of $2.644 \mathrm{Mg} / \mathrm{m}^{3}$ was adopted as $\rho_{\mathrm{s}}$ to calculate $e$ for all depths, $e$ would show a very homogeneous profile. It cannot be judged which one is appropriate between the profiled $\rho_{\mathrm{s}}$ or the constant $\rho_{\mathrm{s}}$. On the other hand, the profile of $\rho_{\mathrm{s}}$ of the Pleistocene clay $\left(=2.695 \pm 0.013 \mathrm{Mg} / \mathrm{m}^{3}\right)$ is very homogeneous with $\mathrm{CV}$ of 0.005 . Because the profiled $\rho_{\mathrm{s}}$ and the constant $\rho_{\mathrm{s}}$ are essentially the same for the Pleistocene clay, the profile of $e$ just corresponds to the profile of $\rho_{\mathrm{t}}$. The large value of $\rho_{\mathrm{t}}$ at EL. $-126.05 \mathrm{~m}$ indicates silty deposit; however, this cannot be clearly confirmed from grain size fractions and SEM images (see Fig. 11).

\section{Variation of Consolidation Properties}

Relationships between void ratio and consolidation stress $\left(e-\log p^{\prime}\right)$ for (a) the Holocene clay and (b) the Pleistocene clay are shown in Fig. 4. All curves for the Holocene and the Pleistocene clays respectively converge on each respective curve under high $p^{\prime}$ range, though ini-
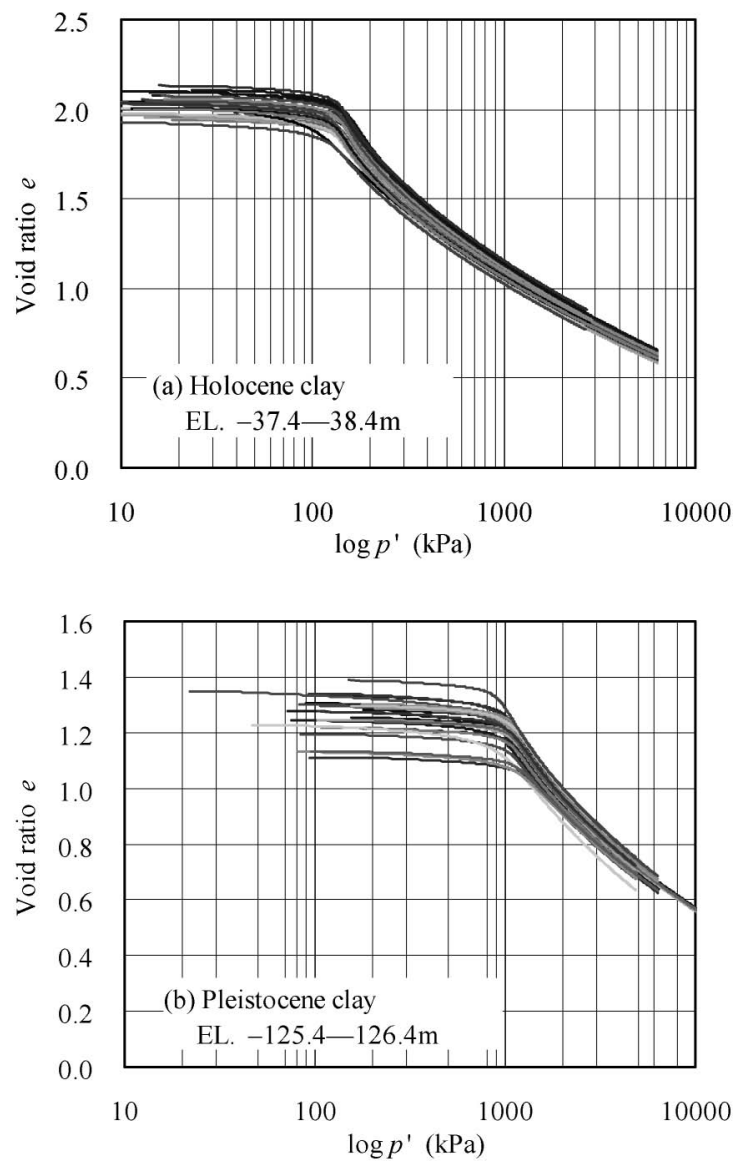

Fig. 4. Relationships between void ratio and consolidation pressure 
(a)

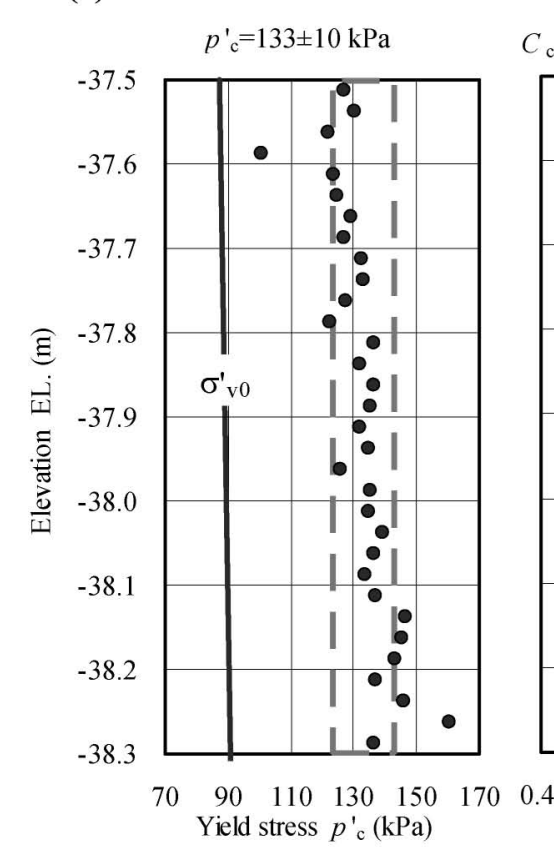

(b)
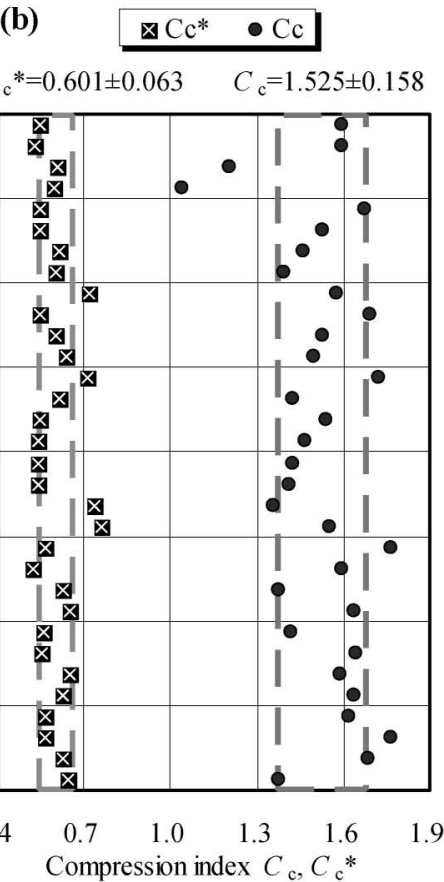

(c)

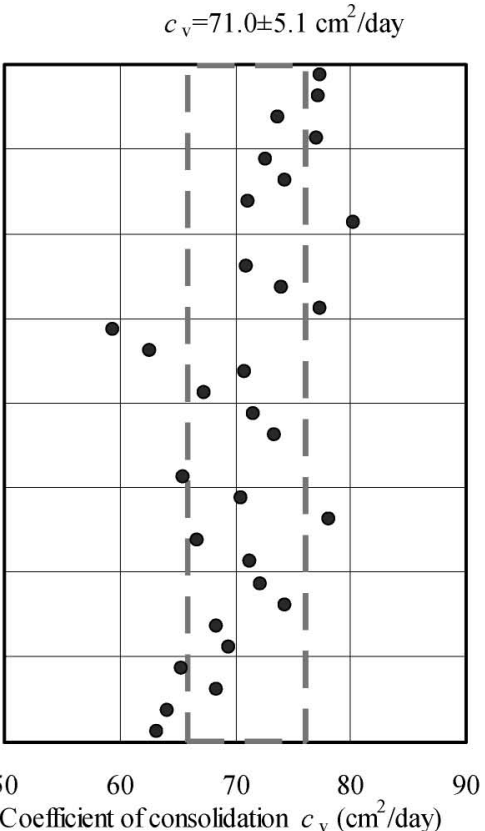

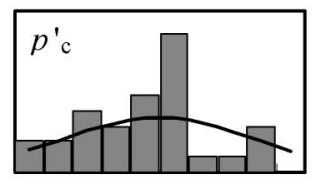

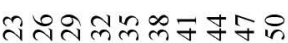

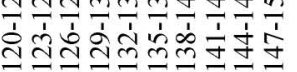

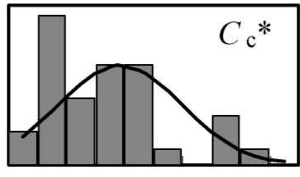

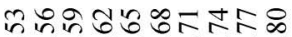

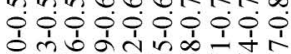

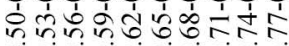

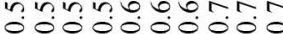

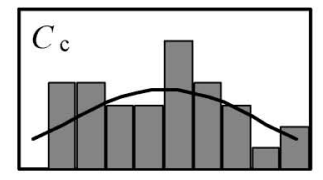

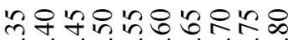

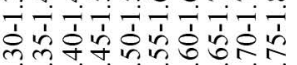

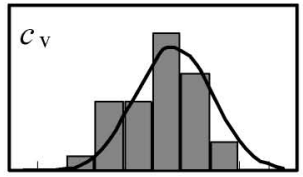

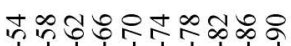

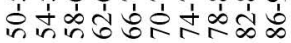

Fig. 5. Profiles of consolidation properties with depth in the Holocene clay

tial $e$ values show some variation. The inversed S-shaped curves with clear yielding, even in the Holocene clay, are characteristically observed for aged natural clays. The curve without a clear yielding point in Fig. 4(a) corresponds to EL. $-37.59 \mathrm{~m}$, and the three curves from smaller $e$ values in Fig. 4(b) correspond to around EL. $-126.05 \mathrm{~m}$. From Fig. 3 which shows slightly smaller $w_{\mathrm{n}}$, slightly larger sand fraction, larger $\rho_{\mathrm{t}}$ and smaller $e$ at EL. $-126.05 \mathrm{~m}$ than those at other depths, the latter is judged to be derived from geological heterogeneity.

Profiles of consolidation parameters $\left(p_{\mathrm{c}}^{\prime}, C_{\mathrm{c}}, C_{\mathrm{c}}^{*}\right.$ and $\left.c_{\mathrm{v}}\right)$ with depth for the Holocene and the Pleistocene clays are shown in Figs. 5 and 6, respectively. In the Holocene clay, $p_{\mathrm{c}}^{\prime}(=133 \pm 10 \mathrm{kPa})$ slightly increases with depth. SD of $C_{\mathrm{c}}$ is 0.158 , but $\mathrm{SD}$ of $C_{\mathrm{c}}^{*}$ is only 0.063 . Variation coefficient $(\mathrm{CV})$, however, is the same as 0.10 for both $C_{\mathrm{c}}$ and $C_{\mathrm{c}}^{*}$. In addition, the specimen from EL. $-37.59 \mathrm{~m}$, corresponding to a smaller $p_{\mathrm{c}}^{\prime}(101 \mathrm{kPa})$ and a smaller $C_{\mathrm{c}}$ (1.043) which are possibly caused by sample disturbance, is not identified in the profile of $C_{\mathrm{c}}^{*}$ which represents compressibility in normal consolidation range.

In the Pleistocene clay, $p_{c}^{\prime}$ is evaluated as $1028 \pm 79$ $\mathrm{kPa}$, but it shows a larger $p_{\mathrm{c}}^{\prime}(1237 \mathrm{kPa})$ at around EL. $-126.05 \mathrm{~m}$. This larger $p_{\mathrm{c}}^{\prime}$ is caused from the unclear yielding shoulder of $e-\log p$ curves as shown in Fig. 4(b). $C_{\mathrm{c}}=0.921 \pm 0.108$ and $C_{\mathrm{c}}^{*}=0.569 \pm 0.048$ are about $40 \%$ and about $5 \%$ smaller than those for the Holocene clay, respectively. The latter (small difference between the clays) indicates that both the Holocene clay and the Pleistocene clay are essentially the same consolidation properties in normal consolidation range. This fact is strongly supported by the same $w_{\mathrm{L}}$ values for the both clays (see Fig. 2). $C_{\mathrm{c}} / C_{\mathrm{c}}^{*}$ is calculated as 1.6 , which is smaller than that of 2.5 calculated for the Holocene clay.

In order to evaluate the variation of $e, p_{\mathrm{c}}^{\prime}, C_{\mathrm{c}}$ and $c_{\mathrm{v}}$, these parameters are normalized by their mean values $\mathrm{MV}$, respectively, and profiles of the normalized parameters of the Holocene clay and the Pleistocene clay with depth are shown in Fig. 7 and 8, respectively.

In the Holocene clay, standard deviation SD values of normalized $e, p_{\mathrm{c}}^{\prime}, C_{\mathrm{c}}$ and $c_{\mathrm{v}}$, i.e. variation coefficient $\mathrm{CV}$ values of $e, p_{\mathrm{c}}^{\prime}, C_{\mathrm{c}}$ and $c_{\mathrm{v}}$, are $0.024,0.075,0.104$ and 0.072 , respectively. $\mathrm{CV}$ of $e(0.024)$ is the smallest and that of $C_{\mathrm{c}}(0.104)$ is the largest among them. In the Pleistocene clay, $\mathrm{CV}$ of $e(0.056)$ is about twice of that in the Holocene clay, which probably caused from the smaller $e$ values at around EL. $-126.05 \mathrm{~m}$. CV of $p_{\mathrm{c}}^{\prime}$ $(0.077)$ is almost the same as that in the Holocene clay. $\mathrm{CV}$ of $C_{\mathrm{c}}(0.117)$ is also the same level as that in the Holocene clay. However, $\mathrm{CV}$ of $c_{\mathrm{v}}(0.109)$ is about $50 \%$ larger than that in the Holocene clay.

Examining the clay samples retrieved from both the 

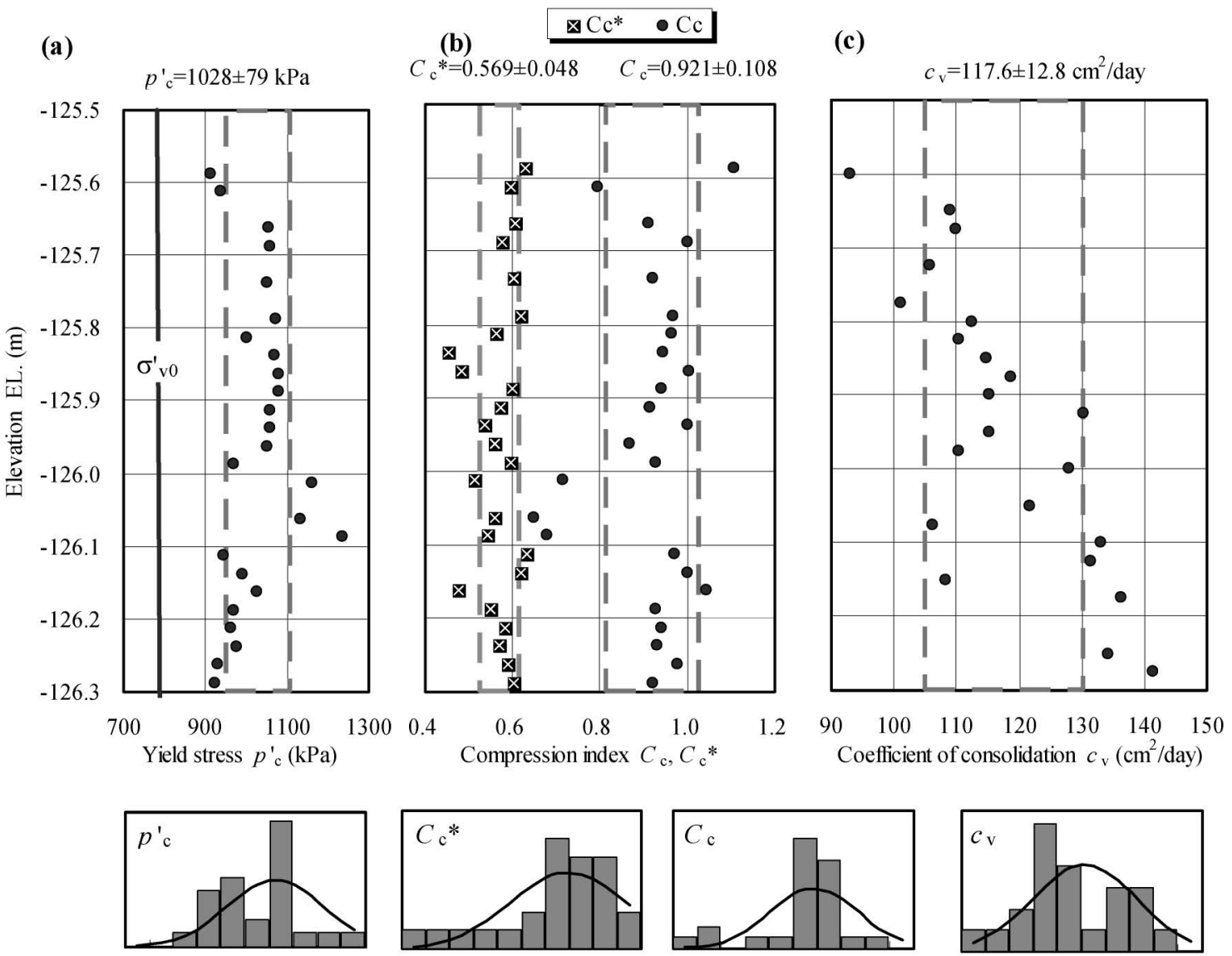

우유응ㅇㅇㅇ웡어융유

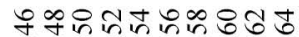

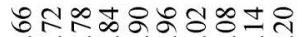

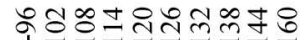

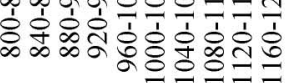

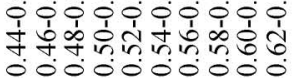

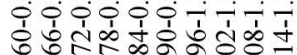

$0000000-1-1$

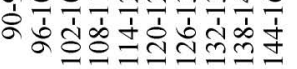

Fig. 6. Profiles of consolidation properties with depth in the Pleistocene clay

(a) $e$

$\mathrm{SD}=0.024$

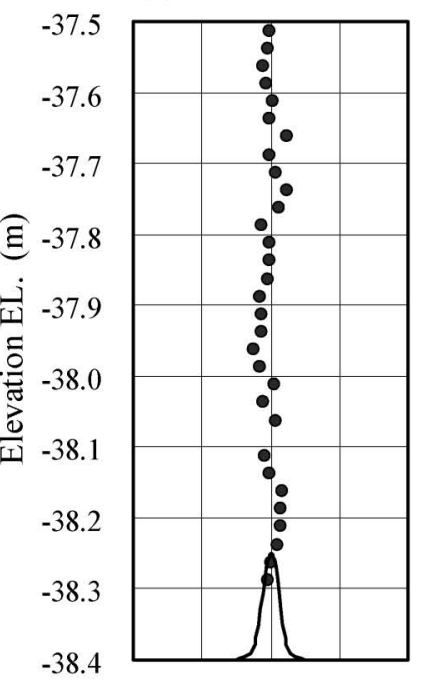

$\begin{array}{llllll}0.6 & 0.8 & 1.0 & 1.2 & 1.4 & 0.6\end{array}$

Normalized $e$ (b) $p^{\prime}{ }_{\mathrm{c}} \quad \mathrm{SD}=0.075$

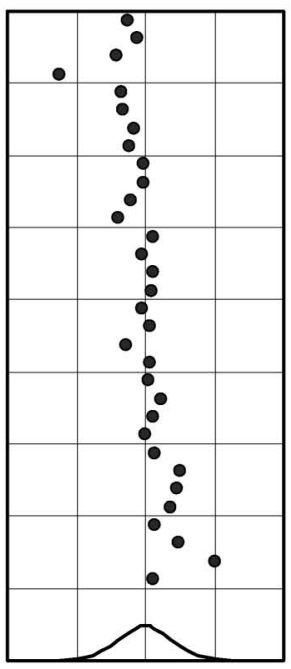

Normalized $p^{\prime}$ (c) $C_{\mathrm{c}}$

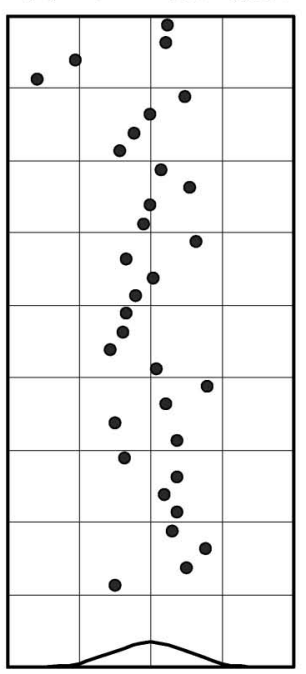

$\begin{array}{lllll}0.8 & 1.0 & 1.2 & 1.4 & 0.6\end{array}$

Normalized $C_{\mathrm{c}}$

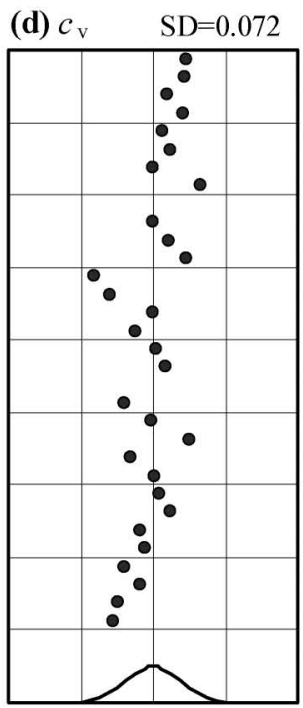

$\begin{array}{llll}0.8 & 1.0 & 1.2 & 1.4\end{array}$

Normalized $c_{\mathrm{V}}$

Fig. 7. Profiles of normalized consolidation parameters with depth in the Holocene clay 

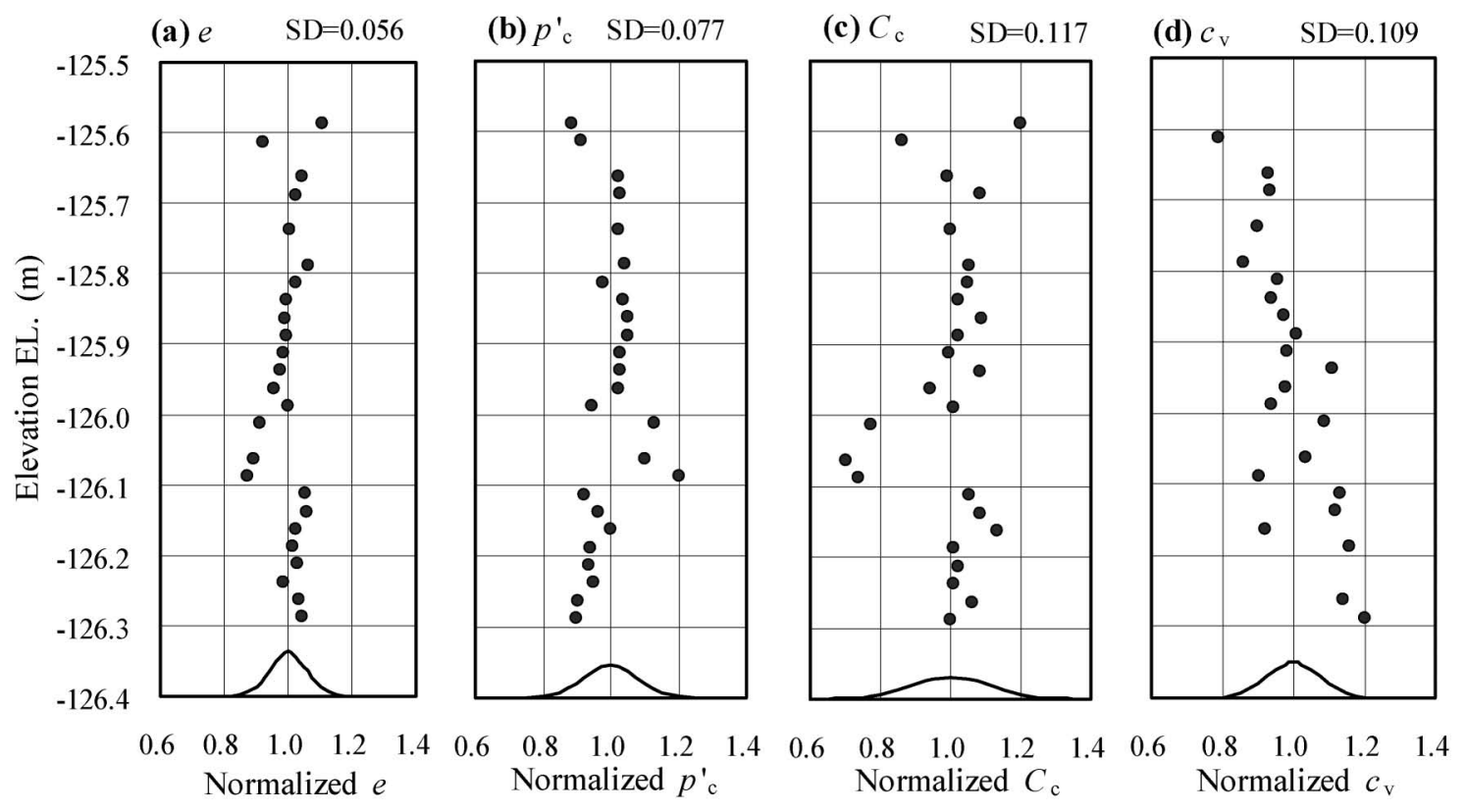

Fig. 8. Profiles of normalized consolidation parameters with depth in the Pleistocene clay

Holocene layer and the Pleistocene layer in Osaka Bay and divided into every $25 \mathrm{~mm}$ of length, it is resulted that the clay layers are relatively homogeneous with $\mathrm{CV}$ of the consolidation parameters $\left(e, p_{\mathrm{c}}^{\prime}, C_{\mathrm{c}}\right.$ and $\left.c_{\mathrm{v}}\right)$ in a range of 0.025 to 0.120 . CV of $e$ is only 0.025 in the Holocene clay and 0.056 in the Pleistocene clay, but CV of the other consolidation parameters $\left(p_{\mathrm{c}}^{\prime}, C_{\mathrm{c}}\right.$ and $c_{\mathrm{v}}$ ) obtained from CRS tests are greater than these values, but the average is less than 0.1 . This value is consistent with the $\mathrm{CV}$ of undrained shear strength profile of Osaka Bay clay $(\mathrm{CV}=$ 0.075 ) indicated in Watabe and Tsuchida (2001b), in which the strength was obtained by the recompression triaxial compression and extension tests proposed by Berre and Bjerrum (1973). Therefore, it can be concluded that $\mathrm{CV}$ values of soil consolidation parameters obtained from CRS tests for the homogeneous natural clay deposits examined in this study are less than about 0.1 .

$\mathrm{MV}$ and $\mathrm{CV}$ of $697 \mathrm{kPa}$ and 0.17 , respectively, for $p_{\mathrm{c}}$ had been obtained from a series of incremental loading oedometer tests separately carried out for the Pleistocene clay (10 results for about $20 \mathrm{~m}$ thick layer). In a case of slight overconsolidation, the representative $p_{\mathrm{c}}$ for the thick layer does not exist, because it increases with depth. Thus, if MV is assumed to represent $p_{\mathrm{c}}$ for the whole layer without regarding the depth profile, CV results a large value. In practice, sampling and laboratory tests are carried out with interval of 1 to $3 \mathrm{~m}$ deep. The middle depth of 0.8 to $1.0 \mathrm{~m}$ long sample represents the depth of the whole sample. The detailed depth of each sample trimmed is not concerned. From the above results obtained in this study, CVs of both physical and consolidation test results are smaller than 0.1 , indicating that it is reasonable to represent as one depth for each sample with about $1 \mathrm{~m}$ long.

Because consolidation parameters are examined every one or a few meter(s) in an ordinary ground survey for practical design, it is difficult to statistically evaluate the variation of obtained parameters if the soil layer is not perfectly homogeneous. Thus, it cannot be judged if the tested specimen was representative of the examining layer or not. Accordingly, it is important to select a representative specimen in the layer in association with the profiles of physical and consolidation properties.

\section{Heterogeneity of Microfabric}

Observed SEM images and those binarized images for the Holocene clay at EL. -37.96 and $-38.19 \mathrm{~m}$ and the Pleistocene clay at EL. -126.01 and $-125.54 \mathrm{~m}$ are shown in Figs. 9, 10, 11 and 12, respectively. In Figs. 9 and 11, the images in magnification of both 5000 and 2500 times show enlarged structure of soil microfabric. On the other hand, in Figs. 10 and 12, the images in magnification of both 5000 and 2500 times show particular parts contained in the soil microfabric such as pyrite (Fig. 10) and diatom (Fig. 12).

Profiles with depth ( $a, b, c$ and $d)$ and frequencies ( $e, f$, $g$ and $h$ ) on black percentage in the binarized black and white images for the Holocene clay and the Pleistocene clay are shown in Figs. 13 and 14, respectively. Here, the black percentage indicates a percentage of pores in the section. Width shown by broken line shows a range of $\mathrm{MV} \pm \mathrm{SD}$. SD value tends to decrease when the magnification decreases as follows: from $9.0 \%$ at 5000 times down to $4.3 \%$ at 500 times for the Holocene clay and from $12.2 \%$ at 5000 times down to $5.7 \%$ at 500 times for the Pleistocene clay.

In the Holocene clay (Fig. 13), SD decreases when the magnification decreases in order of 5000, 2500 and 1000 times, indicating that the impression of the SEM images varies with these magnifications. However, SD values at both magnifications of 1000 and 500 times are in the same level as $4.3 \%$. This fact can be visually impressive in Fig. 

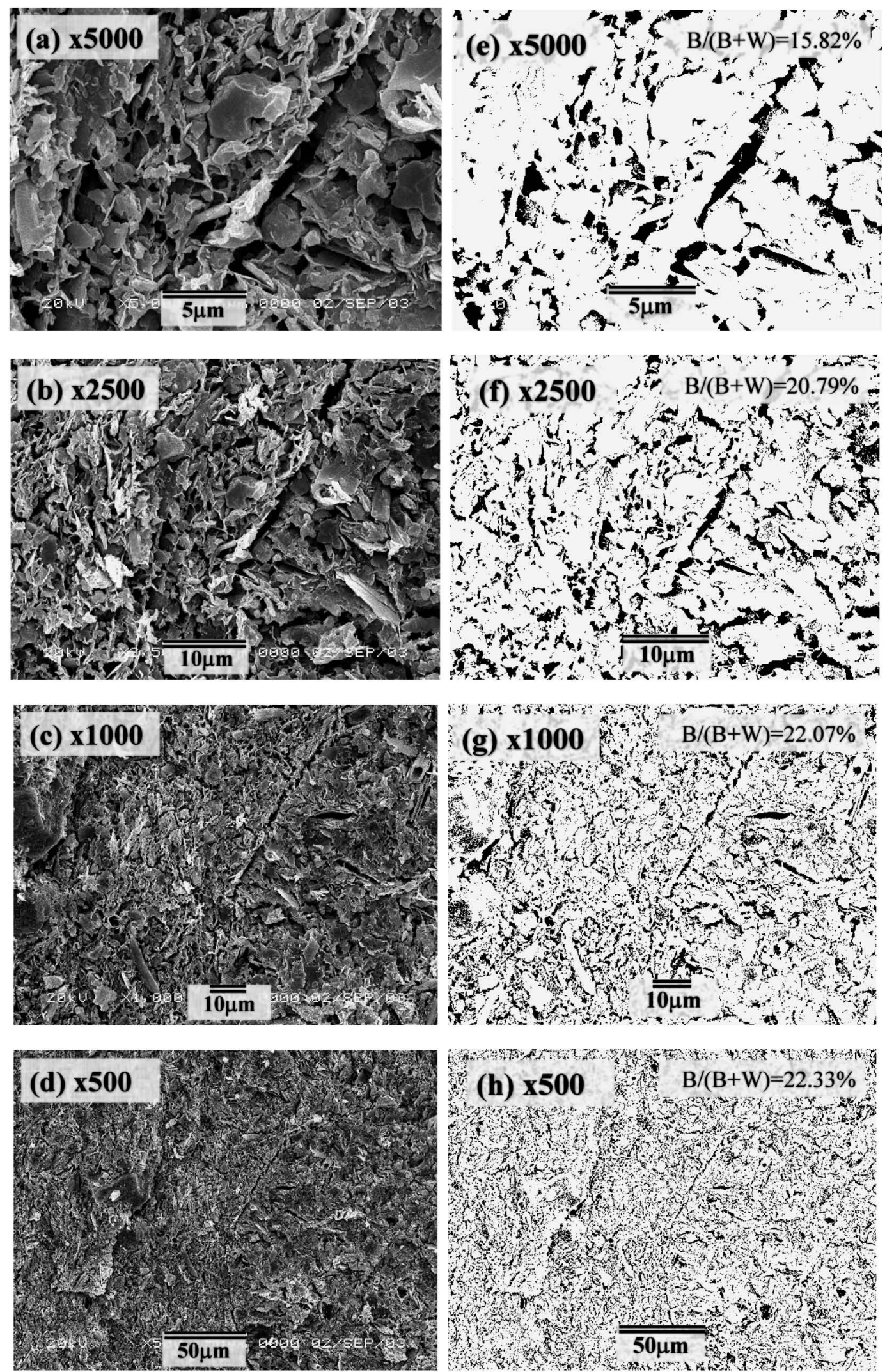

Fig. 9. SEM and binarized images of the Holocene clay at EL. $-37.96 \mathrm{~m}$

9.

In the Pleistocene clay (Fig. 14), SD tends to decrease when the magnification decreases. SD at magnification of 2500 times $(6.3 \%)$ is about half of that at magnification of 5000 times $(12.2 \%)$, but SD values at 2500,1000 , and 500 times are in the same level as around 6\%. This fact can be visually impressive in Fig. 11.

In the Holocene clay, SD values at magnification of 

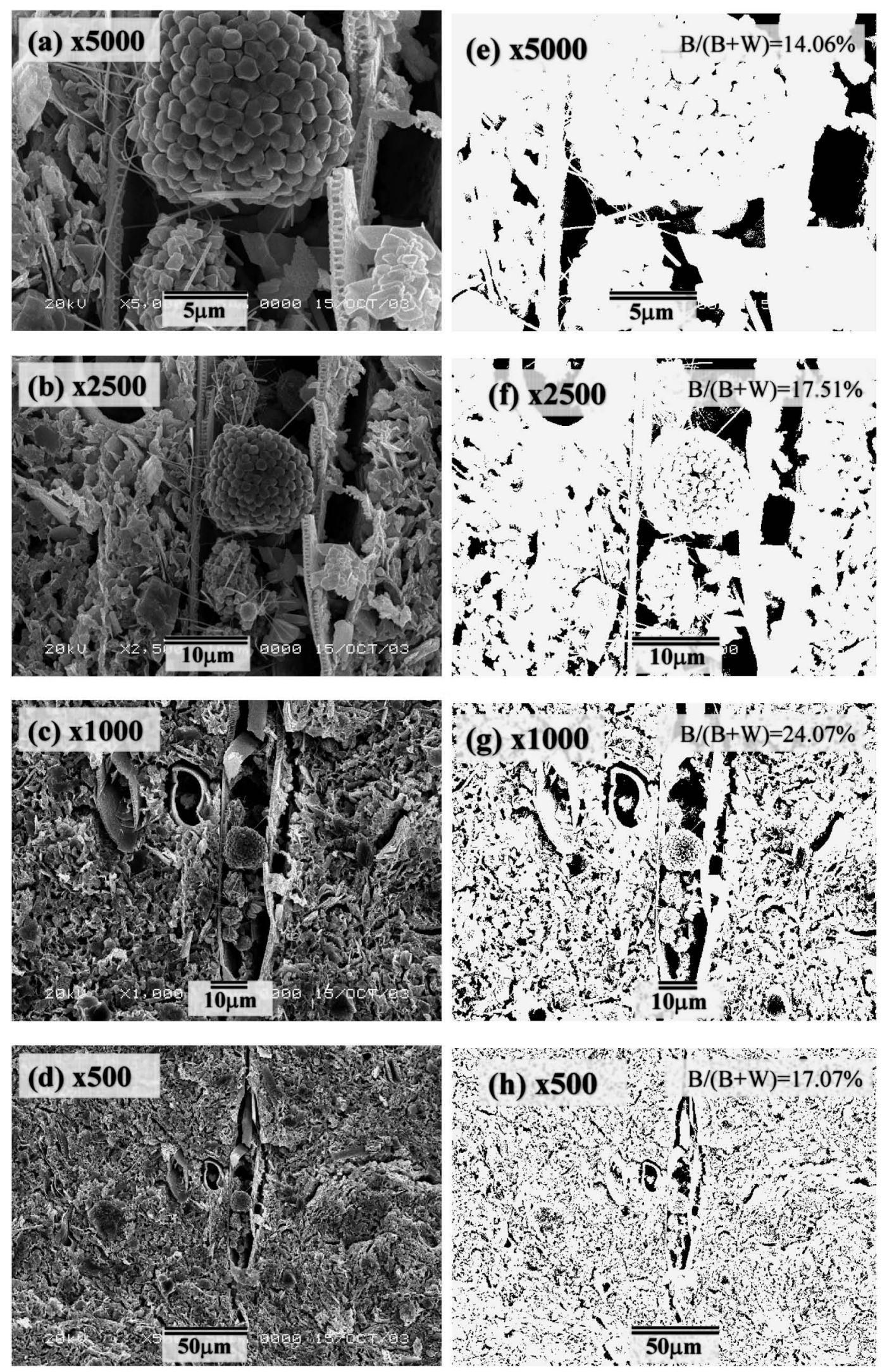

Fig. 10. SEM and binarized images of the Holocene clay at EL. $-38.19 \mathrm{~m}$

2500 times and at magnification of both 1000 and 500 times are $72 \%$ and $48 \%$, respectively, of SD value at magnification of 5000 times. This fact indicates that every SEM image with a high magnification of 5000, 2500 and
1000 times gives different impression, but that every SEM image with a low magnification of 1000 and 500 times gives a similar impression. In the Pleistocene clay, SD value at magnification of 2500 times is $52 \%$ of that at 

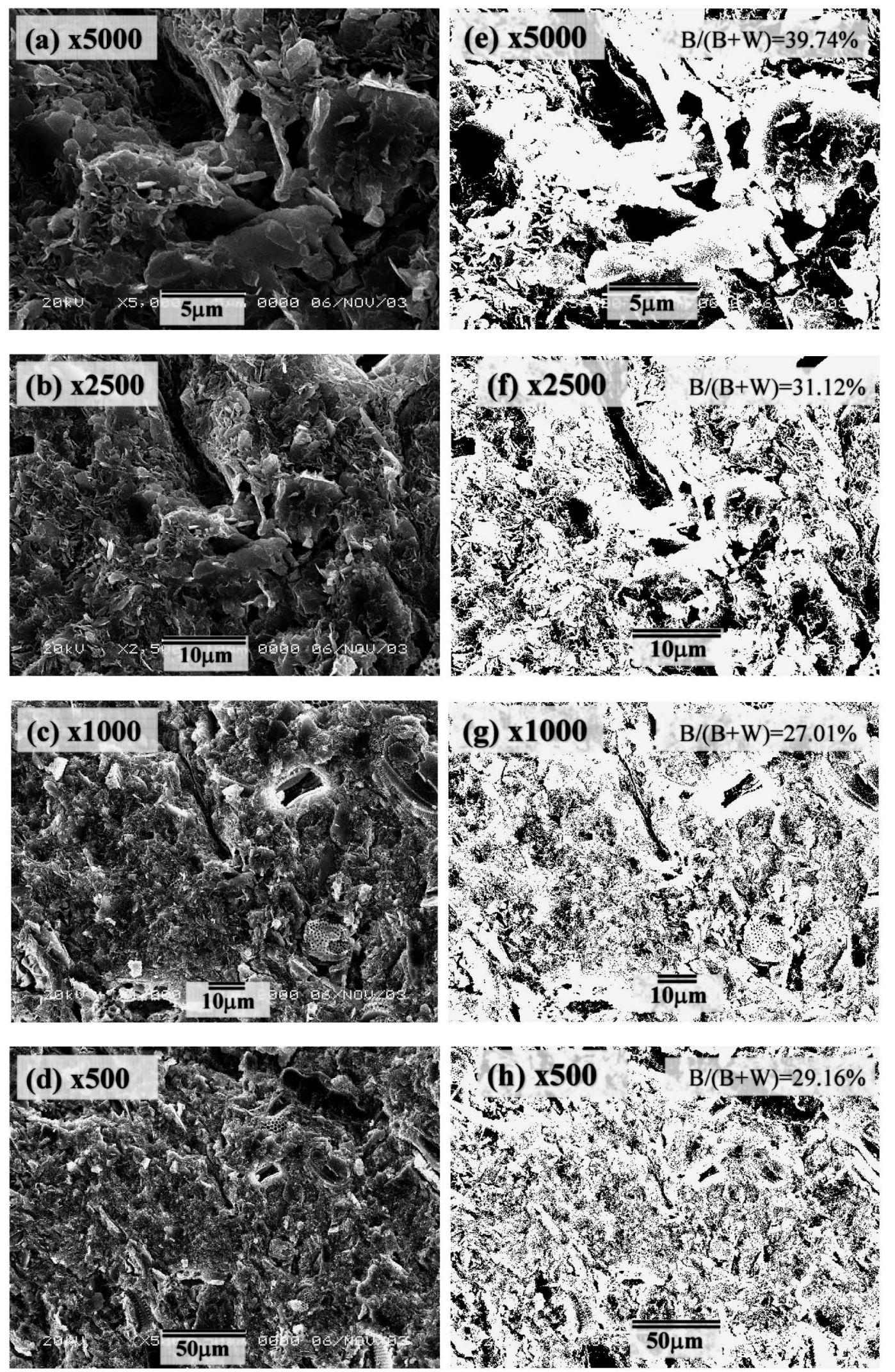

Fig. 11. SEM and binarized images of the Pleistocene clay at EL. $-\mathbf{1 2 6 . 0 1} \mathrm{m}$

magnification of 5000 times, and SD value of 2500, 1000 and 500 times is in the same level. This fact indicates that every SEM image with a high magnification of 5000 and 2500 times gives different impression, but that every SEM image with a low magnification of 2500, 1000 and 500 times gives a similar impression.

Figure 15 shows relationships (a) MV of black percentage and (b) CV of black percentage versus the magnifica- 

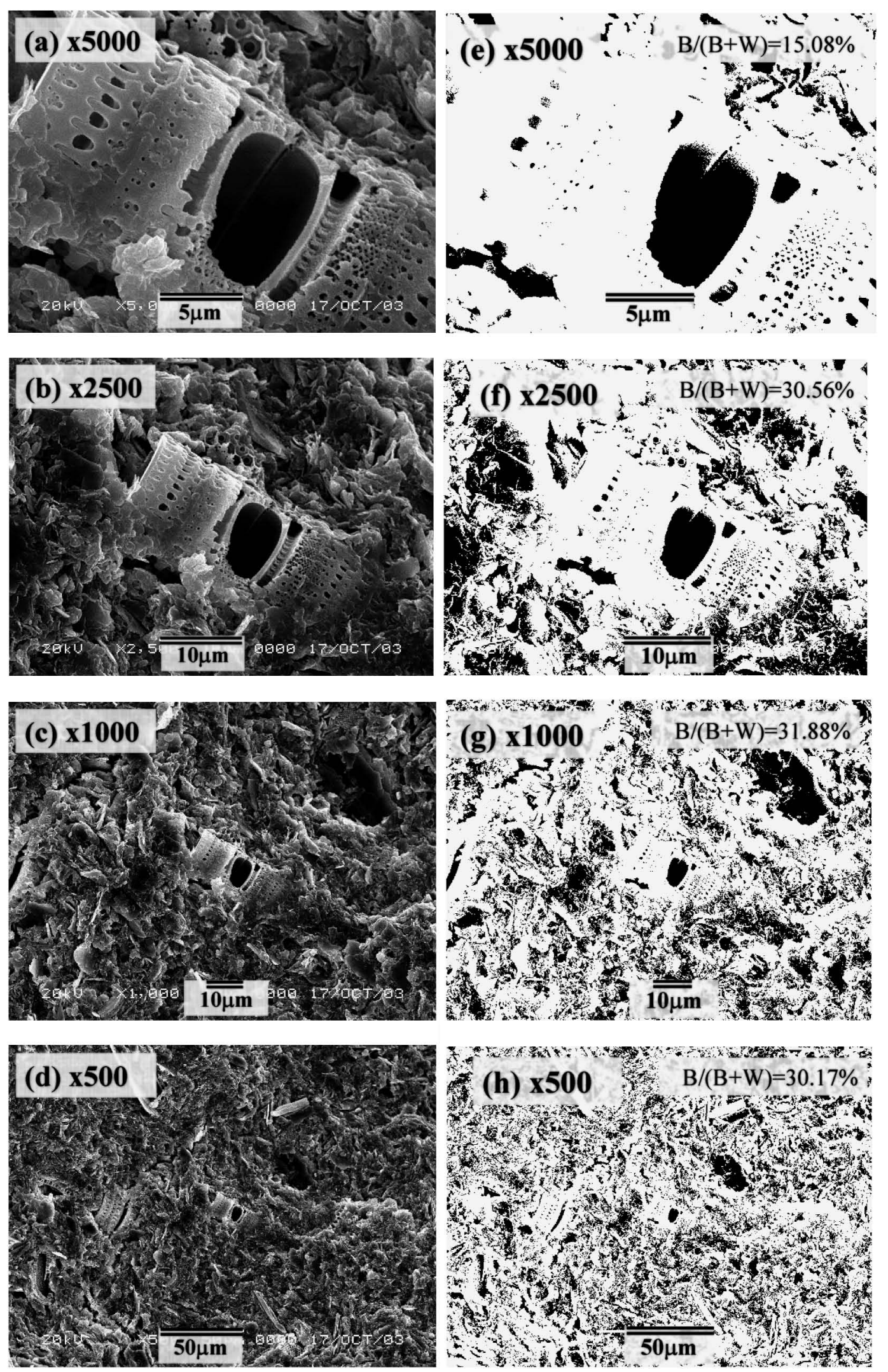

Fig. 12. SEM and binarized images of the Pleistocene clay at EL. $-125.54 \mathrm{~m}$

tion. Because $\mathrm{CV}$ of the black percentage is reflected by the flocculent structure or diatoms, if we observe the specimen in a magnification smaller than the lower limit of magnification corresponding to a constant $\mathrm{CV}$, we can obtain an image which gives us always the same impression. In Fig. 15(a), MV slightly decreases when the magnification increases, but essentially constant. From CV in Fig. 15(b), it can be said that the variation of the SEM im- 

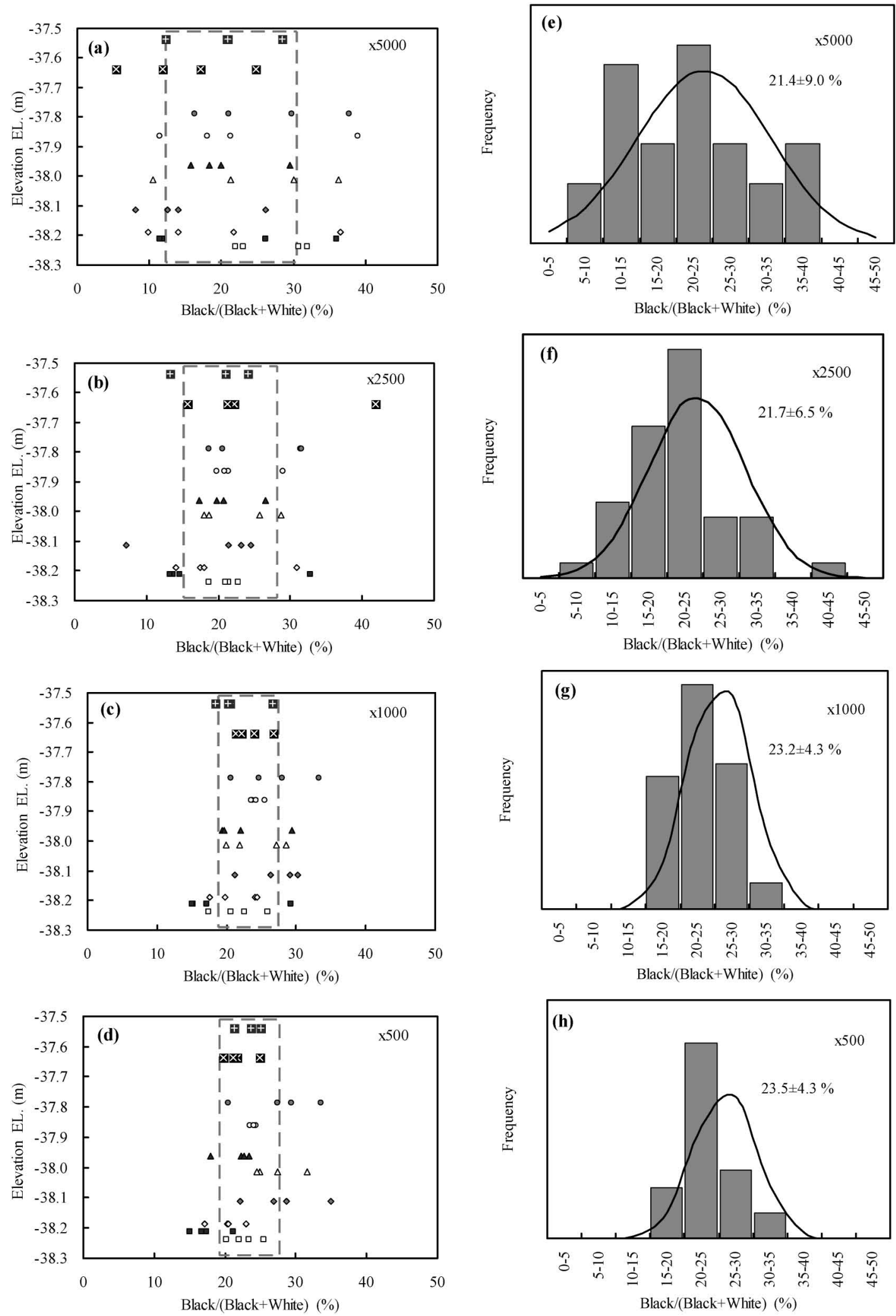

Fig. 13. Profiles of black percentage with depth and frequencies of the binarized images in the Holocene clay

ages becomes significant when observation magnification is greater than 1000 times for the Holocene clay or 2500 times for the Pleistocene clay. Therefore, a representative structure in the microfabric can be observed in an area of $125 \mu \mathrm{m} \times 100 \mu \mathrm{m}$ with magnification of 1000 times for the
Holocene clay or $50 \mu \mathrm{m} \times 40 \mu \mathrm{m}$ with magnification of 2500 times for the Pleistocene clay, respectively. Here, it is of concern that the analyzed results is strongly affected by the threshold value; however, we confirmed that MV and $\mathrm{CV}$ of black percentage increase about $10 \%$ and 

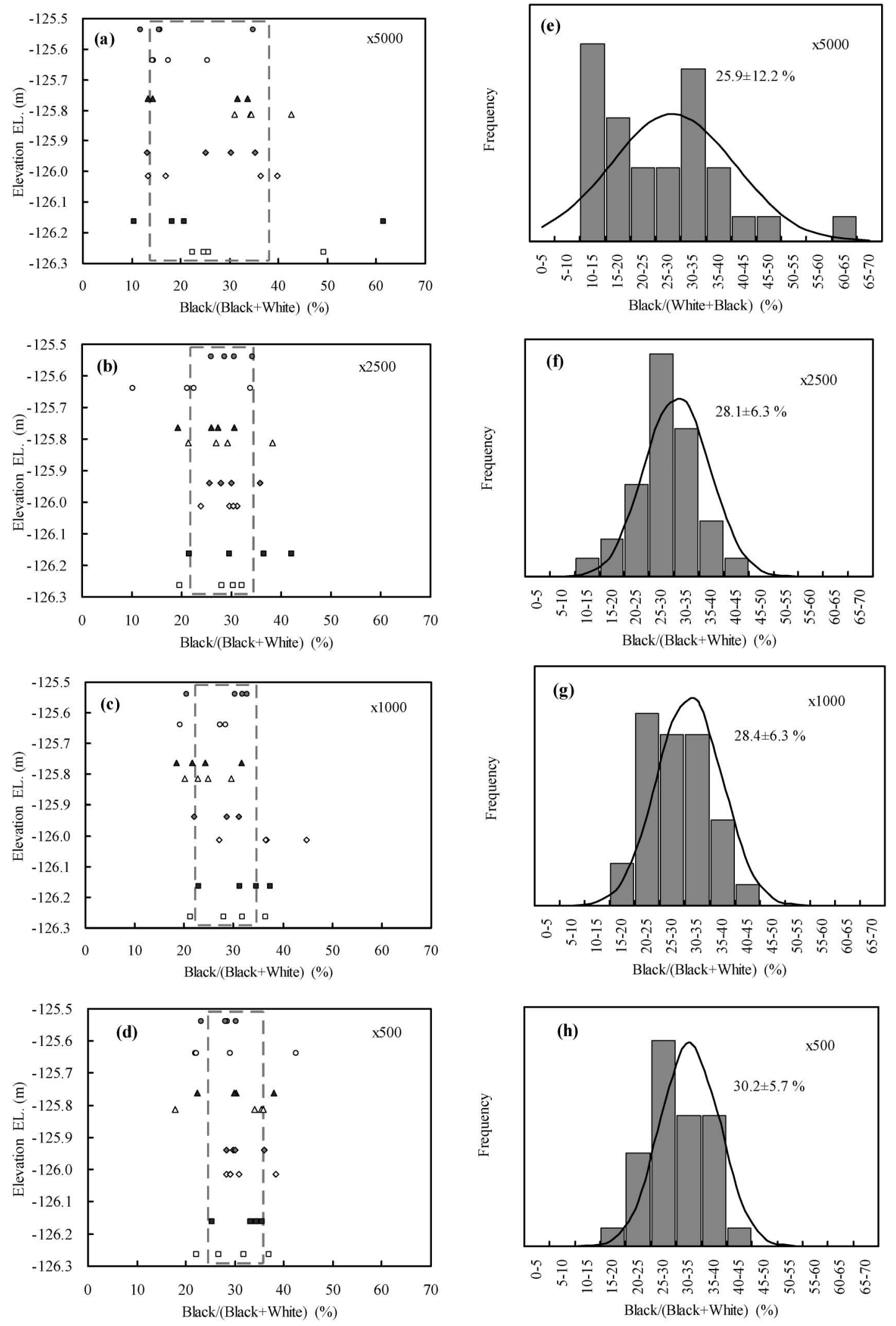

Fig. 14. Profiles of black percentage with depth and frequencies of the binarized images in the Pleistocene clay

remain constant, respectively, if the threshold value decreased from 200 to 190.

Profiles of the most probable pore entrance diameter $D$, which correspond to the peak of $\Delta V_{\mathrm{p}} / \Delta \log D_{\mathrm{p}}$, for (a) the Holocene clay and (b) the Pleistocene clay are shown in Fig. 16. Here, $V_{\mathrm{p}}$ is cumulative pore volume; and $D_{\mathrm{p}}$ is pore entrance diameter obtained from MIP. Width shown by broken line shows a range of $\mathrm{MV} \pm \mathrm{SD}$, which 
is $0.79 \pm 0.18 \mu \mathrm{m}$ for the Holocene clay and $0.28 \pm 0.05$ $\mu \mathrm{m}$ for the Pleistocene clay. Because grain size distributions for the Holocene clay and the Pleistocene clay are similar to each other from the grain size fractions as shown in Figs. 2(b) and 3(b), the SEM image impression discussed above is not governed by grain size distribution

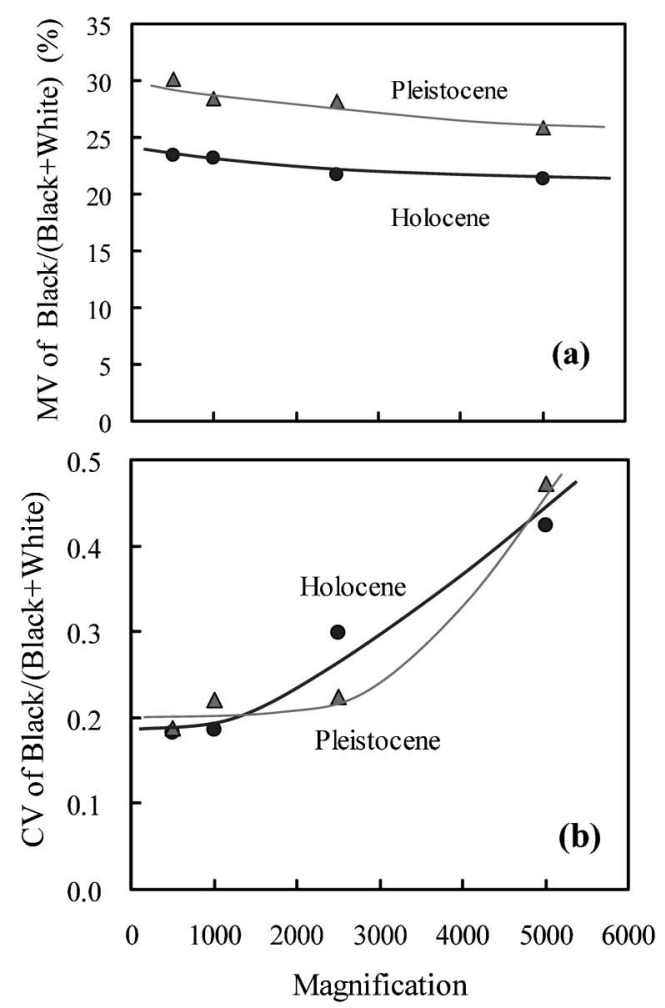

Fig. 15. Relationships of (a) MV of black percentage and (b) CV of black percentage versus the observation magnification

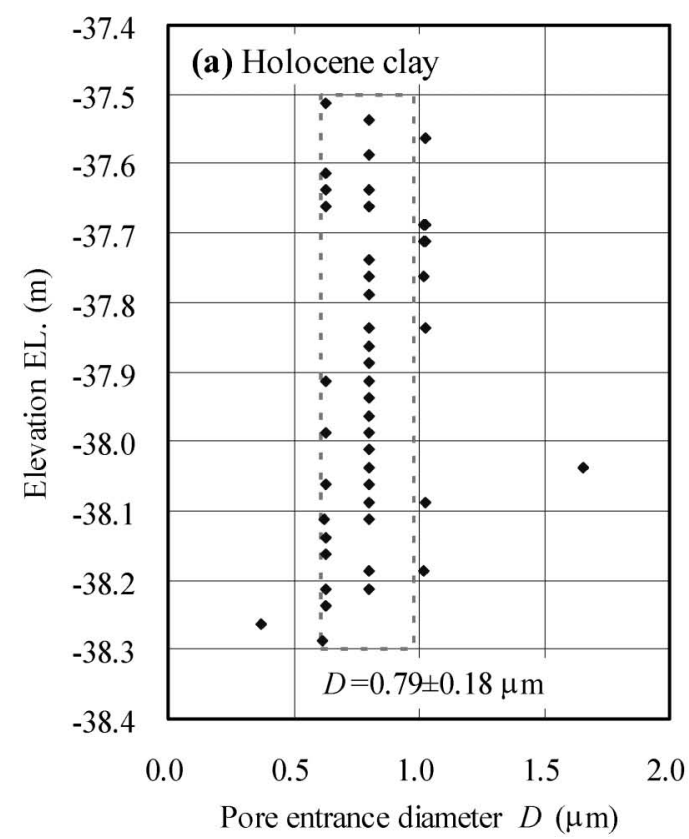

but it may be governed by pore entrance size distribution. A representative SEM image can be obtained in a scale size (e.g. square root of $125 \mu \mathrm{m} \times 100 \mu \mathrm{m}$ for the Holocene clay and that of $50 \mu \mathrm{m} \times 40 \mu \mathrm{m}$ for the Pleistocene clay) corresponding to 150 times of a representative pore entrance diameter $(0.79 \mu \mathrm{m}$ for the Holocene clay and $0.28 \mu \mathrm{m}$ for the Pleistocene clay) or larger. This is probably a key relationship correlating the microfabric with pore structure.

Because the specimen size for laboratory tests is sufficiently large compared to the scale of microscopic heterogeneity discussed with both SEM images and pore entrance size distributions, the variations of physical and consolidation properties are mainly influenced by sedimentary environment, and even the soil is said to be homogeneous.

\section{CONCLUSIONS}

In this study, two clay samples with a length of about one meter retrieved from both the Holocene layer and the Pleistocene layer in Osaka Bay by using thin walled tube sampler with $80 \mathrm{~mm}$ in diameter and about one meter in length were divided into every $25 \mathrm{~mm}$ of length to trim consolidation specimens with $60 \mathrm{~mm}$ in diameter and 20 $\mathrm{mm}$ in height. The objective of this study was to exam the variation of physical and consolidation properties for natural clay deposit in Osaka Bay. Variation of consolidation parameters were examined by using the trimmed specimen. Also, variations of physical properties and microfabric were examined by using soil chips from specimen trimming. The followings are derived as conclusions:

1) The clay layers are very homogeneous with $\mathrm{CV}$ values of physical properties $\left(w_{\mathrm{n}}, \rho_{\mathrm{t}}, \rho_{\mathrm{s}}\right.$ and $\left.e\right)$ in a range of

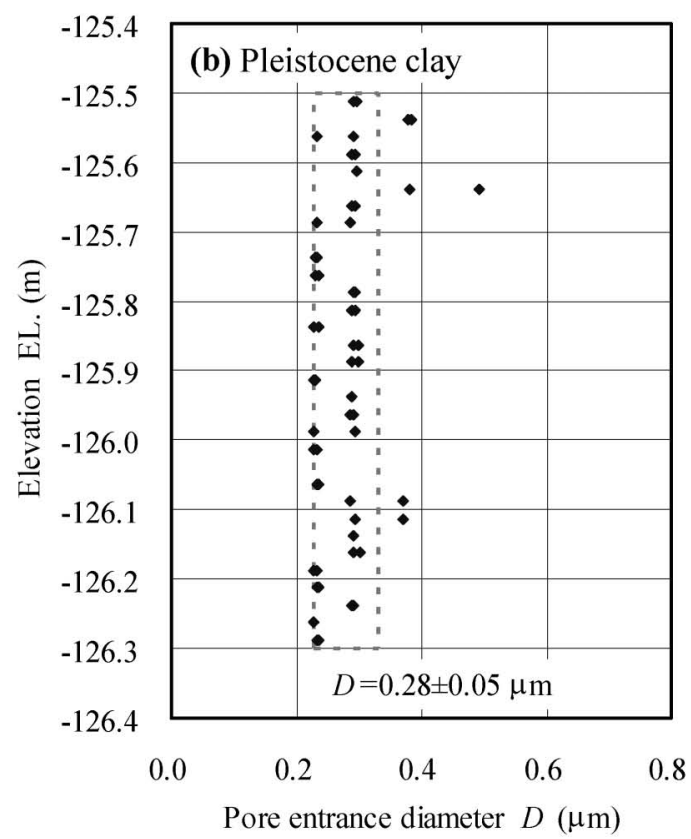

Fig. 16. Profiles of the most probable pore entrance diameter for (a) Holocene clay and (b) Pleistocene clay 
0.005 to 0.056 . $\mathrm{CV}$ of $\rho_{\mathrm{t}}$ and $\rho_{\mathrm{s}}$ is around 0.01 for both the Holocene clay and the Pleistocene clay. CV values of $w_{\mathrm{n}}$ and $e$ are around 0.03 for the Holocene clay and around 0.05 for the Pleistocene clay.

2) The clay layers are relatively homogeneous with $\mathrm{CV}$ values of consolidation parameters $\left(e, p_{\mathrm{c}}^{\prime}, C_{\mathrm{c}}\right.$ and $\left.c_{\mathrm{v}}\right)$ in a range of 0.025 to 0.120 . CV of $e$ is only 0.025 in the Holocene clay and 0.056 in the Pleistocene clay. $\mathrm{CV}$ values of consolidation parameters $\left(p_{\mathrm{c}}^{\prime}, C_{\mathrm{c}}\right.$ and $\left.c_{\mathrm{v}}\right)$ obtained from CRS tests are significantly greater than this, but the average is less than 0.1 . It can be concluded that $\mathrm{CV}$ values of soil consolidation parameters obtained from CRS tests for the homogeneous natural clay deposits examined in this study are less than about 0.1 .

3) From the test results obtained in this study, CVs of both physical and consolidation test results are smaller than 0.1 , indicating that it is reasonable to represent as one depth for each sample with about 1 $\mathrm{m}$ long.

4) It can be said that the variation of SEM images becomes significant when observation magnification is greater than 1000 and 2500 times for the Holocene clay and the Pleistocene clay, respectively. This means that a representative soil microfabric can be observed in an area of $125 \mu \mathrm{m} \times 100 \mu \mathrm{m}$ with a magnification of 1000 times for the Holocene clay and 50 $\mu \mathrm{m} \times 40 \mu \mathrm{m}$ with a magnification of 2500 times for the Pleistocene clay.

5) A representative SEM image can be obtained in a scale size greater than about 150 times of a representative pore entrance diameter. This is a key relationship correlating the microfabric with pore structure.

6) Because specimen sizes for laboratory tests is sufficiently large compared to the scale of microscopic heterogeneity discussed with SEM images and pore entrance size distributions, the variations of physical and consolidation properties are mainly influenced by sedimentary environment, even the soil is said to be homogeneous.

\section{ACKNOWLEDGEMENTS}

The authors would like to thank Ms. Tomoko Takemura of Kinki Regional Development Bureau, Ministry of Land, Infrastructure and Transport for the numerous SEM observations and MIP measurements during her term in Port and Airport Research Institute. The authors would also like to thank Prof. Jacques Locat, Universite Laval, Canada, for his kind advices on the specimen preparation and SEM observation. They also greatly thank Kansai International Airport Land Development Co., Ltd., for offering the clay samples retrieved from the second phase construction site of Kansai International Airport.

\section{REFERENCES}

1) Akai, K. (2000): Insidious settlement of super-reclaimed offshore seabed, Coastal Geotechnical Engineering in Practice, Balkema, 243-248.

2) Akai, K., Nakaseko, K., Matsui, T., Kamon, M, Sugano, K., Tanaka, Y. and Suwa, S. (1995): Geotechnical and geological studies on seabed in Osaka Bay, Proc. 11th European Conference on $S M E F, 8,1-6$.

3) Berre, T. and Bjerrum, L. (1973): Shear strength of normally consolidated clays, Proc. 8th ICSMFE, 39-49.

4) Duncan, J.M. (1993): Limitations of conventional analysis of consolidation settlement, Journal of Geotechnical and Geoenvironmental Engineering, American Society of Civil Engineers, 119(9), 1331-1359.

5) Horie, H., Zen, K., Ishii, I. and Matsumoto, K. (1984): Engineering properties of marine clay in Osaka Bay, (Part-1) Boring and sampling, Technical Note of the Port and Harbour Research Institute, Ministry of Transport, Japan, (498), 5-45 (in Japanese).

6) Ishii, I., Ogawa, F. and Zen, K. (1984): Engineering properties of marine clays in Osaka bay, (Part-2) Physical properties, consolidation characteristics and permeability, Technical Note of the Port and Harbour Research Institute, Ministry of Transport, Japan, (498), 47-86 (in Japanese).

7) Kanda, K., Suzuki, S. and Yamagata, N. (1991): Offshore soil investigation at the Kansai International Airport, Proc. International Conference on Geotechnical Engineering for Coastal Development, Geo-Coast '91, 1, 33-38.

8) Kang, M.-S., Watabe, Y. and Tsuchida, T. (2003): Effect of drying process on the evaluation of microstructure of clays using scanning electron microscope (SEM) and mercury intrusion porosimetry (MIP), Proc. 13th International Offshore and Polar Engineering Conference, 385-392.

9) Nakase, A. (1987): Kansai international airport-construction of man-made island, Proc. 8th Asian Regional Conference on SMFE, 2, 87-101.

10) Shi, B., Wu, Z., Inyang, H., Chen, J. and Wang, B. (1999): Preparation of soil specimens for SEM analysis using freeze-cut-drying, Bulletin of Engineering Geology and the Environment, 58, 1-7.

11) Tanaka, H. and Locat, J. (1999): A microstructural investigation of Osaka Bay clay: the impact of microfossils on its mechanical behaviour, Canadian Geotechnical Journal, 36(3), 493-508.

12) Tanaka, H., Ritoh, F. and Omukai, N. (2003a): Geotechnical properties of clay deposits of the Osaka Basin, Characterisation and Engineering Properties of Natural Soils, Swets \& Zeitlinger, 455-474.

13) Tanaka, H., Tanaka, M., Suzuki, S. and Sakagami, T. (2003b): Development of a new cone penetrometer and its application to great depths of Pleistocene clays, Soils and Foundations, 43(6), 51-61.

14) Tsuchida, T., Kikuchi, Y., Nakashima, K. and Kobayashi, M. (1984): Engineering properties of marine clays in Osaka Bay, (Part3) Static characteristics of shear, Technical Note of the Port and Harbour Research Institute, Ministry of Transport, Japan, (498), 87-114 (in Japanese).

15) Watabe, Y. and Tsuchida, T. (2001a): Influence of stress release on sample quality of Pleistocene clay collected fro large depth in Osaka Bay, Soils and Foundations, 41(4), 17-24.

16) Watabe, Y. and Tsuchida, T. (2001b): Comparative study on undrained shear strength of Osaka Bay Pleistocene clay determined by several kinds of laboratory test, Soils and Foundations, 41(5), 45-59.

17) Watabe, Y., Tsuchida, T. and Adachi, K. (2002): Undrained shear strength of Pleistocene clay in Osaka Bay, Journal of Geotechnical and Geoenvironmental Engineering, American Society of Civil Engineers, 128(3), 216-226.

18) Watabe, Y., Hikiyashiki, H., Kang, M.-S., Tanaka, M. and Takemura, T. (2004): Microstructure of clay observed by SEM in consideration of specimen preparation method, Proc. 15th Southeast Asian Geotechnical Conference, Bangkok, 21-26. 